\title{
Eugenol alleviated breast precancerous lesions through HER2/ PI3K-AKT pathway-induced cell apoptosis and S-phase arrest
}

\author{
Min $\mathrm{Ma}^{1, *}$, Yi Ma ${ }^{2, *}$, Gui-Juan Zhang ${ }^{3, *}$, Rui Liao ${ }^{1}$, Xue-Feng Jiang ${ }^{1}$, Xian-Xin Yan ${ }^{1}$, \\ Feng-Jie Bie ${ }^{1}$, Xiao-Bo Li ${ }^{1}$ and Yan-Hong Lv ${ }^{1}$ \\ ${ }^{1}$ College of Traditional Chinese Medicine, Institute of Integrated Traditional Chinese and Western Medicine, Jinan University, \\ Guangzhou 510632, Guangdong Province, China \\ ${ }^{2}$ Institute of Biomedicine, Department of Cellular Biology, Key Laboratory of Bioengineering Medicine of Guangdong Province, \\ Jinan University, Guangzhou 510632, Guangdong Province, China \\ ${ }^{3}$ The First Affiliated Hospital of Jinan University, Guangzhou 510632, Guangdong Province, China \\ *These authors contributed equally to this work
}

Correspondence to: Min Ma, email: 1019312292@qq.com, tmamin@jnu.edu.cn

Keywords: eugenol, breast precancerous lesion, HER2/PI3K-AKT, external use, cell apoptosis

Received: February 18, 2017 Accepted: April 19, 2017 Published: May 05, 2017

Copyright: Ma et al. This is an open-access article distributed under the terms of the Creative Commons Attribution License 3.0 (CC BY 3.0 ), which permits unrestricted use, distribution, and reproduction in any medium, provided the original author and source are credited.

\section{ABSTRACT}

Eugenol can be separated from the oil extract of clove bud, and has many pharmacological functions such as anticancer and transdermal absorption. HER2/PI3KAKT is a key signaling pathway in the development of breast cancer. In this study, 80 $\mu M$ eugenol could significantly inhibit the proliferation of HER-2 positive MCF-10AT cells and the inhibition rate was up to $32.8 \%$, but had no obvious inhibitory effect on MCF7 and MCF-10A cells with HER2 weak expression. Eugenol also significantly induced human breast precancerous lesion MCF-10AT cell apoptosis and cell cycle S-phase arrest, but the biological effects nearly disappeared after HER2 over-expression through transfecting PCDNA3.1-HER2. In MCF-10AT cells treated by $180 \mu \mathrm{M}$ eugenol, the protein expressions of HER2, AKT, PDK1, p85, Bcl2, NF-KB, Bad and Cyclin D1 were decreased and the decreased rates were respectively $63.0 \%, 60.0 \%, 52.9 \%, 62.9 \%$, $37.1 \%, 47.2 \%, 61.7 \%, 59.1 \%$, while the p21, p27 and Bax expression were increased by 4.48-, 4.76- and 2.57-fold respectively. In the rat models of breast precancerous lesion, $1 \mathrm{mg}$ eugenol for external use significantly inhibited the progress of breast precancerous lesion and the occurrence rate of breast precancerous lesions and invasive carcinomas was decreased by about $\mathbf{3 0 . 5 \%}$. Furthermore eugenol for external (1 mg) markedly decreased the protein expressions of HER2 $(62.9 \%)$, AKT $(58.6 \%)$, PDK1 (56.4\%), p85 (54.3\%), Bcl2 (59.3\%), NF-kB (65.7\%), Bad (64.0\%), Cyclin D1 $(43.0 \%)$, while p21, p27 and Bax protein expressions were respectively increased 1.83-, 2.52- and 2.51-fold. The results showed eugenol could significantly inhibit the development of breast precancerous lesions by blocking HER2/PI3K-AKT signaling network. So eugenol may be a promising external drug for breast precancerous lesions.

\section{INTRODUCTION}

Breast cancer accounts for about $29 \%$ of female malignancies, and breast cancer mortality rates rank the first in female cancer patients. The development of breast cancer goes through the continuous process containing normal, hyperplasia, atypical hyperplasia and carcinoma. Precancerous lesion, the essential stage of breast cancer progression, can be blocked or reversed via specific drug intervention. Thereby, the incidence of breast cancer can be effectively decreased due to the block for tumor development process [1].

Probability of malignant tumors resulted from precancerous lesions was more than $20 \%$, notably, breast precancerous lesions mainly including atypical hyperplasia (atypical ductal or lobular hyperplasia), 
ductal carcinoma in situ, ductal carcinoma, papillary tumor, resulted in approximately $50 \%$ probability of breast cancer occurring. Hoogerbruggeet et al found that the incidence rates of precancerous lesion, atypical lobular hyperplasia, atypical ductal hyperplasia, small leaf in situ, and ductal carcinoma in situ were respectively $57 \%, 37 \%, 39 \%, 25 \%$ and $15 \%$ in the susceptible population of breast cancer. Moreover, the incidence with high risk of breast cancer was significantly increased after 40 years of age [2].

Currently, the relationship between precancerous lesion and breast cancer, and the regular pattern of continuously developmental process in breast cancer are being studied by more and more researchers. It was found that breast hyperplasia, precancerous lesion and invasive cancer could appear simultaneously in the histopathological sections of breast cancer, and the relationship between precancerous lesion and breast cancer was closer than breast hyperplasia, which also revealed that precancerous lesion was an important early-stage in the development of breast cancer. On the contrary, if breast precancerous lesions can be kept from the pathogenic factors or intervened effectively by therapeutics, it may stay in a stable state for a long time and even get good reverse recovery. HER2/PI3KAKT signal transduction pathway plays an important role in breast cancer occurrence and the signal transduction network formed by HER2/PI3K-AKT signaling pathway is closely related to the occurrence, development and treatment of breast cancer [3, 4]. However, the relationship between breast precancerous lesions and HER2/PI3KAKT signal transduction pathway is not clear so far.

Studies have shown that tamoxifen (Tam) can be used for the treatment of breast precancerous lesions and early prevention of breast cancer. There is no significant difference between the clinical curative effect of Tam external and oral use. Moreover, Tam external use has a function of sustained release properties compared with oral use. In addition, some studies also showed that Tam external use can obviously inhibit breast precancerous lesions, reduce the blood flow rate of local microcirculation, adjust the levels of pituitary and sex hormone, decrease oxygen free radicals and accelerate metabolism so as to further block the development of breast cancer through acting as estrogen receptor antagonist $[5,6]$. However, Tam is prone to cause endocrine disorders, liver and kidney damage $[7,8]$.

Eugenol (Eug) [4-allyl (-2-mthoxyphenol), molecular formula: $\mathrm{C}_{10} \mathrm{H}_{12} \mathrm{O}_{2}$ ], a phenolic natural compound available in honey and in the essential oils of different spices such as clove, bay leaves and cinnamon leaf, has been exploited for various medicinal applications. Eug has a variety of pharmacological activities such as analgesic, antiseptic, antioxidant, antibacterial, anticancer, anti-inflammatory and so on [9]. Al-Sharifet et al proved that Eug could trigger apoptosis in breast cancer cells through E2F1/survivin down-regulation and also inhibit the growth of breast cancer tissues in vitro [10]. Kumar et al indicated clove had significant growth inhibition effect on MCF-7 cell line of breast cancer by brine shrimp lethality test (BSLT) and 3-(4,5)-dimethylthiahiazo(-z-y1)3,5-di-phenytetrazoliumromide (MTT) determination [11]. Hussain et al showed that there was a synergistic effect between Eug and gemcitabine (an anticancer drug), which could improve the therapeutic index of cancer, and Eug could significantly reduced the expression of $\mathrm{Bcl} 2, \mathrm{COX}-2$ and IL-1 $\beta$ [12]. These results indicate that Eug can resist cancer by inducing apoptosis and its anti-inflammatory properties.

In this study, BT-474, MCF-7, MCF-10A, MCF10AT cells and model rats of breast precancerous lesions were treated with different concentrations of Eug to study the biological effects of Eug on anti-breast precancerous lesions and its mechanism of inducing apoptosis and cell cycle arrest by affecting HER2/PI3K-AKT signaling pathway.

\section{RESULTS}

\section{Eug might significantly inhibit cells proliferation through blocking the target HER2}

The BT-474, MCF-10AT, MCF-7 and MCF$10 \mathrm{~A}$ cells in logarithmic growth phase were treated by different concentrations of Eug (40, 80, 120, 160, 200 and $240 \mu \mathrm{M}$ ) for $24 \mathrm{~h}$, and the cells growth inhibition rates were detected. After the cells were treated by different concentrations of Eug for $24 \mathrm{~h}$, MCF-10AT cells growth could be significantly inhibited. The $50 \%$ inhibiting concentration (IC50) of Eug on HER-2 positive MCF10AT cells was $160.9 \mu \mathrm{M}$. In BT-474, MCF-10AT, MCF-7 and MCF-10A cells with HER2 over-expression through transfecting plasmid pcDNA3.1-HER2, the protein expression levels of HER2 were respectively 3.14-, 2.37-, 4.32- and 3.53-fold of the corresponding controls (Figure 1A). As shown in Figure 1B, the inhibition rates of $80 \mu \mathrm{M}$ Eug and Tam on MCF-10AT were $32.8 \%$ and $28.9 \%$ respectively, which were significantly higher than PBS-treated group (blank control). The inhibition rate of Eug $(80 \mu \mathrm{M})$ in MCF-10AT cells with HER2 overexpression was only $6.7 \%$ and showed no significant difference compared with PBS-treated group (Figure 1B). Eug $(80 \mu \mathrm{M})$ had no obvious inhibitory effect on MCF-7 and MCF-10A cells with HER2 weak expression, but the inhibition rates of Eug significantly increased in MCF-7 and MCF-10A cells with HER2 over-expression (Figure 1B). The inhibition rate of $80 \mu \mathrm{M}$ Eug for BT-474 cells with HER2 high expression was up to $43.3 \%$, but the inhibition effect basically disappeared in BT-474 cells with HER2 over-expression (Figure 1B). These results showed that Eug might significantly inhibit MCF-10AT and BT474 cells proliferation through blocking the target HER2. 


\section{Eug could significantly promote MCF-10AT cells apoptosis}

MCF-10AT cells and MCF-10AT cells with HER2 over-expression in logarithmic phase inoculated in 6-well plate were treated with PBS, Tam or Eug $(180 \mu \mathrm{M})$ for $24 \mathrm{~h}$. Then the effects of Eug on the apoptosis of MCF-10AT cells were determined by AnnexinV-FITC/PI double stainingflow cytometry. The experimental results showed that MCF-10AT cell apoptosis rates were respectively $5.00 \%$, $20.73 \%$ and $11.50 \%$ in PBS-, Eug-, and Tam-treated groups (Figure 2A and 2B). The apoptosis rate of PBS-treated group showed no significant difference compared with Eugtreated MCF-10A cells with HER2 over-expression group. MCF-10AT cells apoptosis rates of Eug- and Tam-treated groups were obviously higher than that of PBS-treated group, suggesting that Eug and Tam could significantly promote MCF-10AT cells apoptosis. The apoptosispromoting effect of Eug on MCF-10AT cells disappeared after overexpressing HER2 (Figure 2A and 2B).

\section{Eug could significantly induce $S$-phase cell cycle arrest in breast precancerous lesion MCF-10AT cells}

MCF-10AT cells and MCF-10AT cells with HER2 over-expression in logarithmic growth phase inoculated in 6-well plate with $1 \times 10^{5}$ cells/well were treated with PBS, Tam or Eug $(180 \mu \mathrm{M})$ for $24 \mathrm{~h}$. The PI single staining-flow cytometry was applied to determine the effects of Eug on cell cycle of MCF-10AT cells. As shown in Figure 3A and $3 \mathrm{~B}$, the results showed that the cell percentages of G0/G1, S and G2/M phases were $74.29 \%, 13.91 \%$ and $11.80 \%$ respectively in Eug-treated group, whereas the cell percentages of $\mathrm{G} 0 / \mathrm{G} 1, \mathrm{~S}$ and $\mathrm{G} 2 / \mathrm{M}$ phases were $84.49 \%, 5.69 \%, 9.84 \%$ in PBS-treated group. The analysis showed that MCF-10AT cells remaining in S phase were significantly increased by $8.22 \%$ after the treatment of Eug for $24 \mathrm{~h}$, correspondingly, the cells remaining in G0/G1 phase and G2/M phase were reduced by $8.24 \%$, furthermore the decrease of the cells remaining in $\mathrm{G} 0 /$ G1 phase was main and the number of G2/M phase cells has no significant changes (Figure 3A and 3B). However, the biological effect of Eug inducing S-phase cell cycle arrest basically disappeared in MCF-10AT cells with HER2 over-expression. This indicated that Eug could block the transformation of cells from S to G2/M phase, thereby inhibiting cell proliferation, compared with Eug, Tam showed a weaker ability in reducing S-phase arrest (3.53\%). Furthermore, as shown in Figure 3C, the protein expression of CDK1, CDK2, Cdc25C and Cyclin A which are mainly involved in driving the transition from $\mathrm{S}$ to G2/M phase were markedly reduced in Eug-treated HER2 non-overexpressing MCF-10AT cells. The results showed that Eug could significantly induce S-phase cell cycle arrest in MCF-10AT cells, and the effect was obviously stronger than Tam.
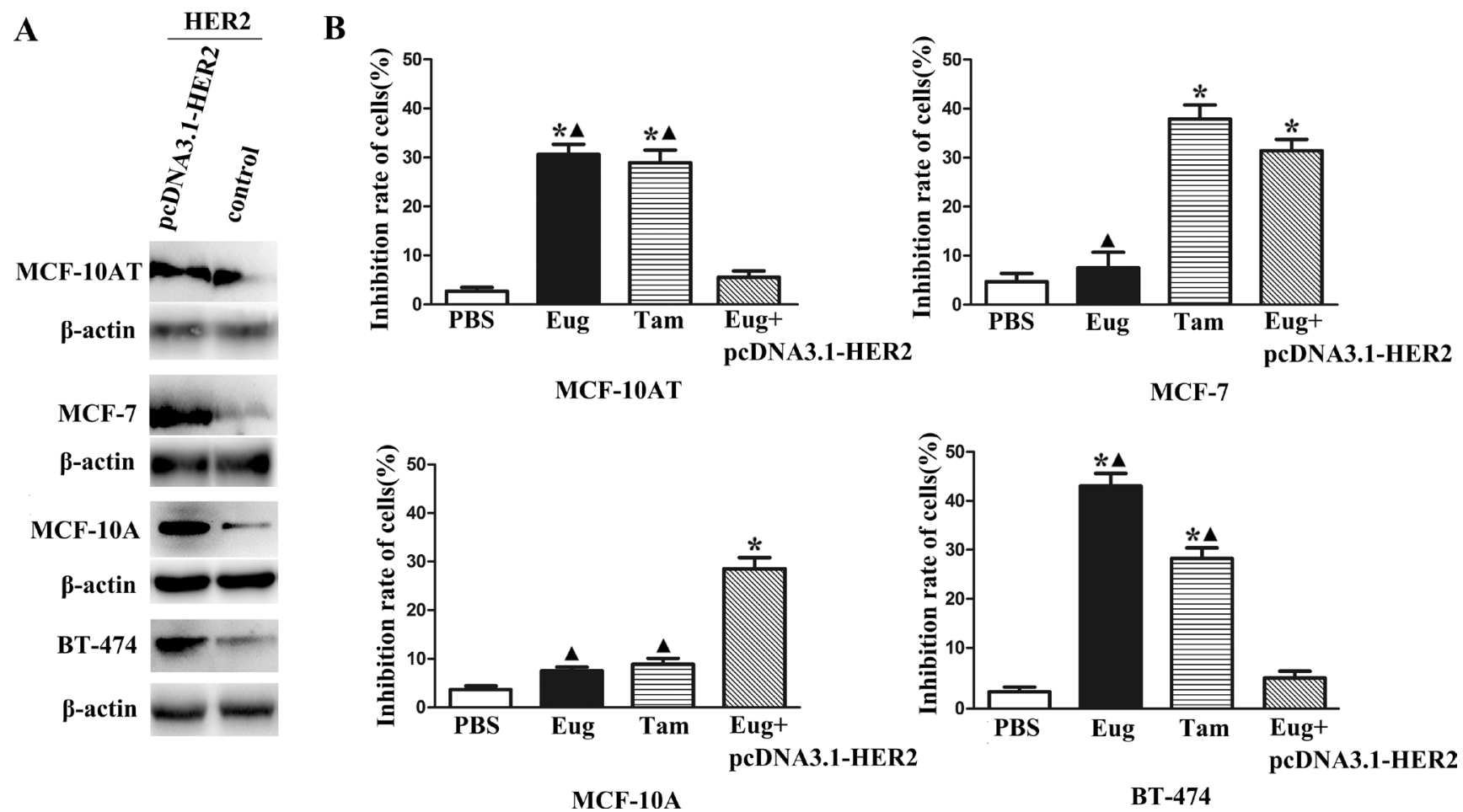

Figure 1: Overexpression of HER2 in BT-474, MCF-10AT, MCF-7 and MCF-10A cells (A) and inhibitory effects on proliferation of eugenol (Eug), tamoxifen (Tam) on HER2 non-overexpressing and overexpressing BT-474, MCF-10AT, MCF-7 and MCF-10A cells (Eug+pcDNA3.1-HER2) (B). ${ }^{*} P<0.05$, Eug, Tam or (Eug+pcDNA3.1-HER2) versus PBS; $\boldsymbol{\Delta} P<0.05$, Eug, Tam or PBS versus (Eug+pcDNA3.1-HER2) (Scheff'e test, $n=3$ ). 


\section{Effects of Eug on the key protein molecules expressions of HER2/PI3K-AKT signaling pathway in MCF-10AT cells}

MCF-10AT cells in logarithmic growth phase inoculated in a 96-well plate were treated with Eug (100, 140 or $180 \mu \mathrm{M})$, Tam $(180 \mu \mathrm{M})$, PBS and the blank matrix (Mat, $40 \mathrm{~g}$ stearic acid was heated in a water bath, melted and cooled down to $80^{\circ} \mathrm{C} .100 \mathrm{~g} \mathrm{KOH}$ water solution and

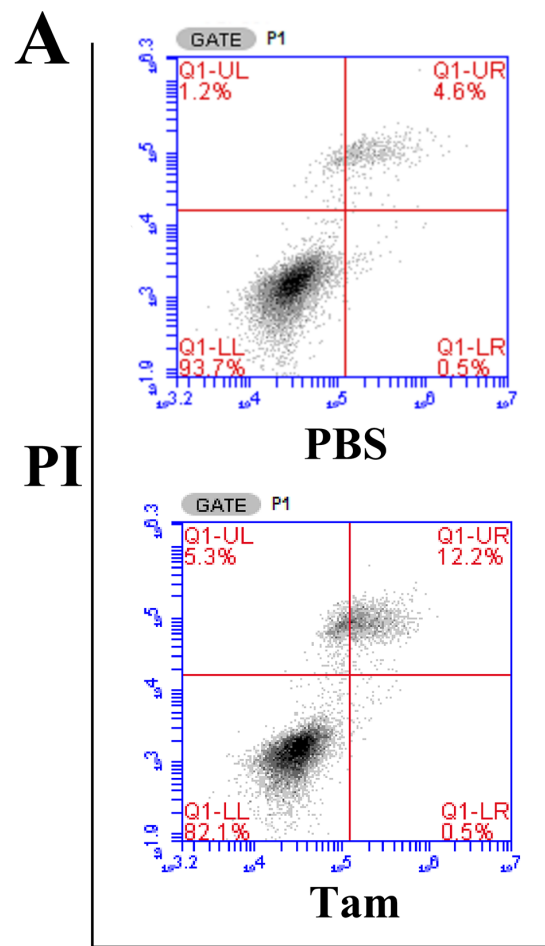

glycerinum were added and stirred constantly, then the appropriate amount of distilled water was added and the volume was metered to $1000 \mathrm{ml}$, so as to obtain the blank matrix, the different doses of Eug were added into Mat, thoroughly mixed and cooled down to room temperature, so as to obtain the Eug cream) for $24 \mathrm{~h}$. The experimental results showed that HER2 protein expression almost showed no difference between the PBS-treated group and Mat-treated group. Compared with PBS-treated group
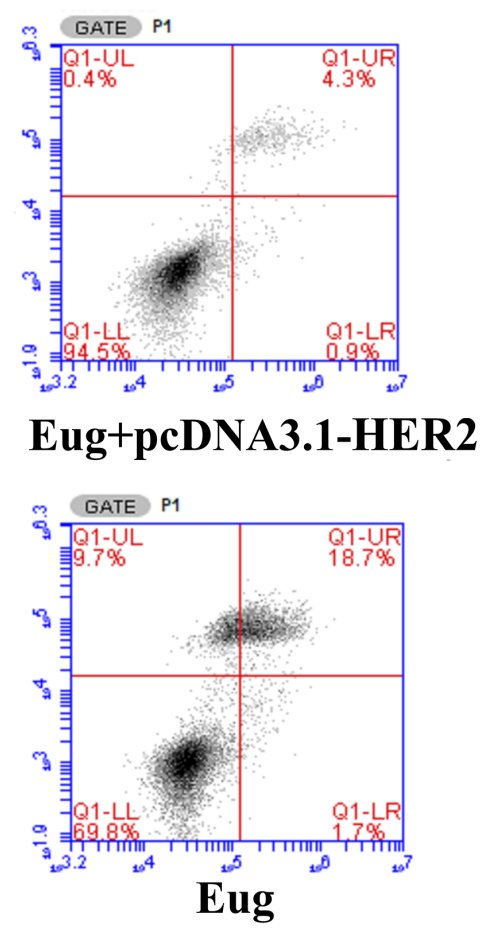

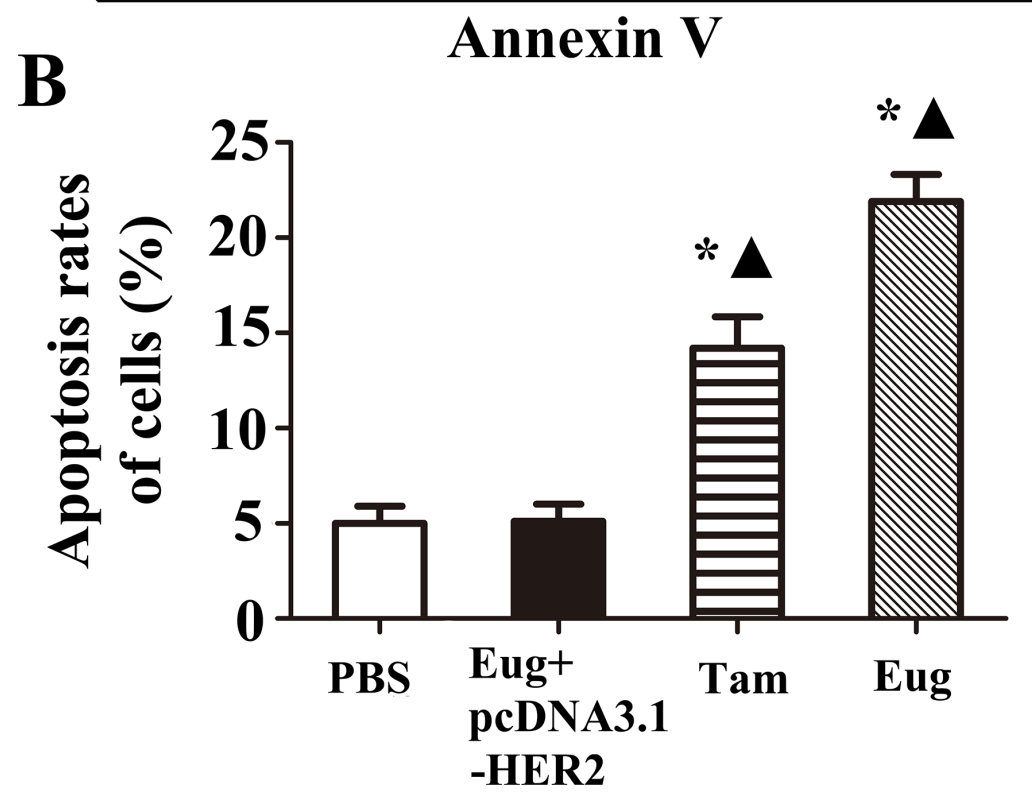

Figure 2: Eugenol (Eug) increased apoptosis for human breast precancerous lesion MCF-10AT cells. (A) Representing assays of tamoxifen (Tam) and Eug inducing apoptosis for HER2 non-overexpressing and overexpressing (Eug+pcDNA3.1-HER2) MCF10AT cells by Annexin V-FITC/PI double staining-flow cytometry. (B) Statistics and data analysis of apoptosis in MCF-10AT cells in (A). PBS was taken as the control group (Vehicle). ${ }^{*} P<0.05$, Eug, Tam or (Eug+pcDNA3.1-HER2) versus PBS; $\mathbf{\Lambda} P<0.05$, Eug, Tam or PBS versus (Eug+pcDNA3.1-HER2) (Scheff'e test, $n=3$ ). 
or Mat-treated group, HER2 protein expression was significantly decreased in Tam-treated group and different concentrations of Eug-treated groups, and Eug had a dosedependent effect. HER2 protein expression was lowest in $180 \mu \mathrm{M}$ Eug-treated group, and HER2 protein expression was decreased by about 51.1\% (Figure 4A and 4B).

As shown in Figure 5, compared with the PBStreated group, the expressions of PDK1, p85 and AKT proteins in MCF-10AT cells were also respectively decreased by $52.9 \%, 62.9 \%$ and $60 \%$ in $180 \mu \mathrm{M}$ Eugtreated group, and the effects were stronger than Tamtreated group. In Eug-treated group the expressions of apoptosis-related factors NF- $\kappa \mathrm{B}, \mathrm{Bad}$ and Bcl-2 were also respectively decreased by $47.2 \%, 61.7 \%$ and $37.1 \%$, while the Bax protein expression was increased by 2.57 -fold (Figure 5A and 5B).

Compared with PBS-treated group, the expressions of cell cycle-associated protein cyclin D1, P21 and p27 were significantly changed in $180 \mu \mathrm{M}$ Tam- and Eug-treated groups. In $180 \mu \mathrm{M}$ Eug-treated group the expression of cyclin D1 was decreased by $59.1 \%$, while P21 and p27 protein expression was significantly increased by 4.48-, 4.76-fold, respectively (Figure 5A and 5B).

Eug might induce S-phase arrest and promote MCF-10AT apoptosis through blocking HER2/PI3KAKT signaling transduction by firstly decreasing HER2 protein expression and further regulating its downstream key signaling molecules expressions in HER2/PI3K-AKT signaling pathway.

\section{Eug cream had effective therapeutic intervention effects on breast precancerous lesion model rats}

\section{Breast tissue morphological observation}

In light of the pathomorphological characteristics, the precancerous lesion and invasive carcinoma did not occur in the normal blank control group. But varying degrees of precancerous lesions and invasive carcinomas occurred in the disease model group, Tam-, high dose Eug creamand low dose Eug-treated model rats groups (Figure 6A
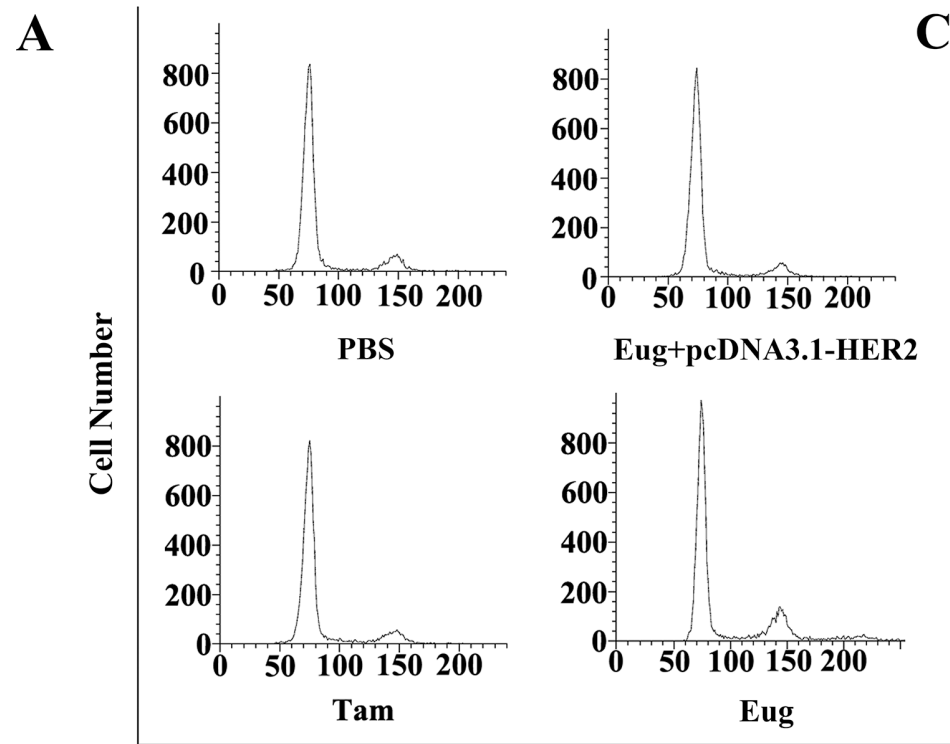

C

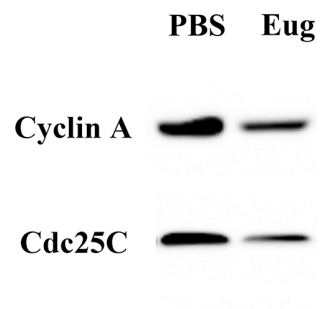

CDK 1

CDK 2

Tubulin

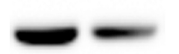

DNA Content
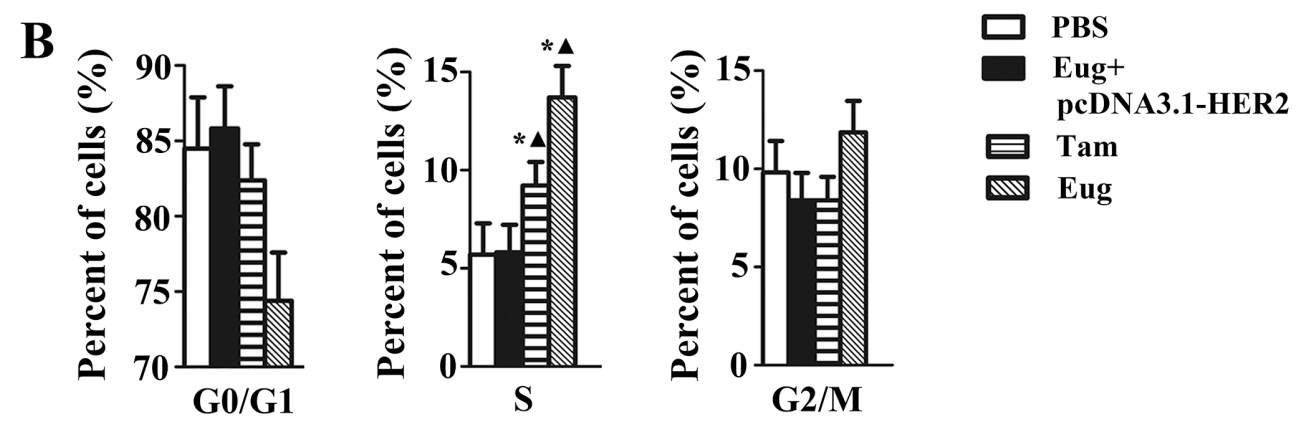

Figure 3: Eugenol (Eug) induced S-phase cell cycle arrest in HER2 non-overexpressing MCF-10AT cells. (A) Flow cytometry assays of the cells cycle for PBS-, Eug- or tamoxifen (Tam)-treated MCF-10AT cells and Eug-treated HER2 overexpressing MCF-10AT cells (Eug+pcDNA3.1-HER2). (B) Statistics and data analysis of MCF-10AT cells cycle distribution in (A). (C) Western-blot assays of CDK1, CDK2, Cdc25C and Cyclin A which are mainly involved in driving the transition from $\mathrm{S}$ to $\mathrm{G} 2 / \mathrm{M}$ phase. $* P<0.05$, Eug, Tam or (Eug+pcDNA3.1-HER2) versus PBS; $\boldsymbol{\Delta} P<0.05$, Eug, Tam or PBS versus (Eug+pcDNA3.1-HER2) (Scheff' $e$ test, $n=3$ ). 
and $6 \mathrm{~B})$. The pathomorphology of the disease model group showed typical precancerous lesion characteristics, which were significantly different from the normal blank control group, suggesting that DMBA in combination with estrogen and progesterone could successfully replicate breast precancerous lesions rat model (Figure 6A and 6B). After being treated by Tam and Eug creams for 14 weeks, compared with the disease model group, the occurrence and development of precancerous lesions and invasive carcinomas were decreased, and the occurrence rates of breast precancerous lesions and invasive carcinomas were respectively decreased by about $40.9 \%-30.5 \%$ and $27.7 \%$ in Tam-, high dose Eug- and low dose Eug-treated groups (Table 1, Figure 6B).

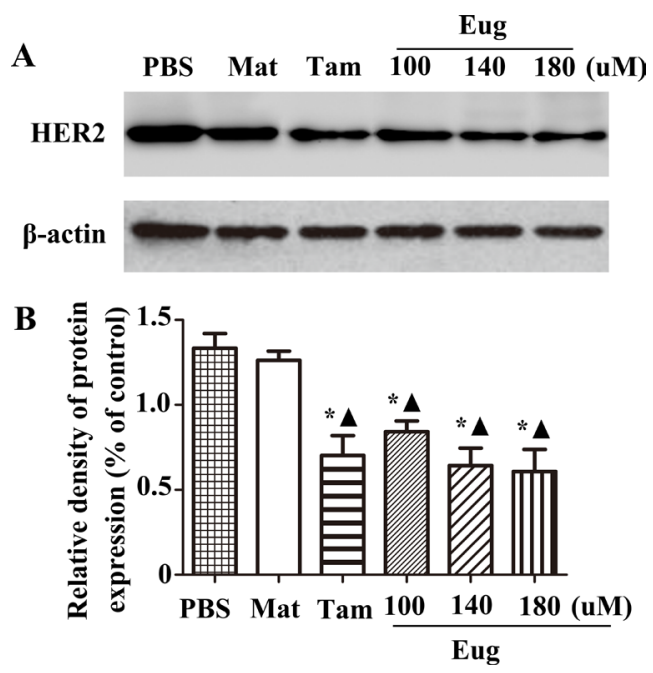

Figure 4: Eugenol (Eug) significantly inhibited the protein expression of HER2. (A) Western-blot assays of HER2 expression at $24 \mathrm{~h}$ after PBS, blank matrix (Mat), Eug or tamoxifen (Tam) treatment in MCF-10AT cells. (B) Relative expression assays for HER2 in (A). PBS and Mat were taken as the blank control groups. ${ }^{*} P<0.05$, Eug $(100,140$ or $180 \mu \mathrm{M})$, Tam or Mat versus PBS; $\boldsymbol{\Delta} P<0.05$, Eug $(100,140$ or $180 \mu \mathrm{M})$, Tam or PBS versus Mat (Scheff'e test, $n=3)$.
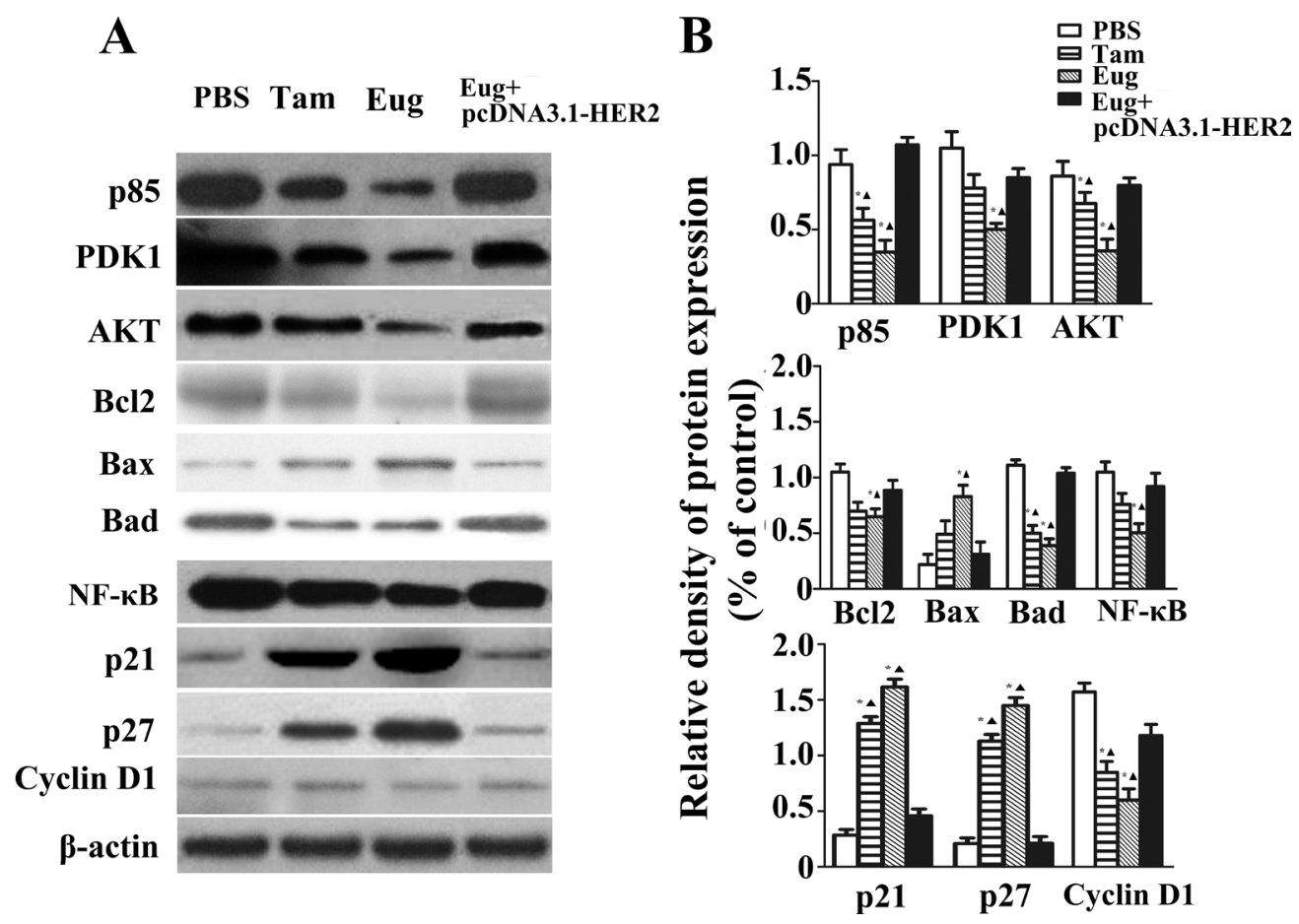

Figure 5: Effect of eugenol (Eug) on the expressions of key proteins P85, PDK1, AKT, Bcl2, Bax, Bad, NF-кB, p21, p27 and Cyclin D1 in HER2/PI3K-AKT signaling pathways in MCF-10AT cells. (A) Western-blot assays of key protein expressions at $24 \mathrm{~h}$ in PBS-, Eug- or tamoxifen (Tam)- treated MCF-10AT cells and Eug-treated HER2 overexpressing MCF-10AT cells (Eug+pcDNA3.1HER2). (B) Relative expression assays for P85, PDK1, AKT, Bcl2, Bax, Bad, NF- $\kappa B$, p21, p27 and Cyclin D1 in (A). ${ }^{*} P<0.05$, Eug, Tam or (Eug+pcDNA3.1-HER2) versus PBS; $\boldsymbol{\Delta} P<0.05$, Eug, Tam or PBS versus (Eug+pcDNA3.1-HER2) (Scheff'e test, $n=3$ ). 
Table 1: Statistical analysis of the pathological changes of the breast tissues in normal or breast precancerous lesion model rats without treatment or continuously treated with tamoxifen (Tam, $1 \mathrm{mg})$, low (0.5 mg) or high (1 mg) dose eugenol (Eug) for 14 weeks

\begin{tabular}{|l|c|c|c|c|c|}
\multicolumn{1}{c}{ Groups } & Breast number & No hyperplasia & $\begin{array}{c}\text { General } \\
\text { hyperplasia }\end{array}$ & $\begin{array}{c}\text { Precancerous } \\
\text { lesions }\end{array}$ \\
\hline Normal & 144 & $126 \boldsymbol{\Delta}$ & $18 \boldsymbol{\Delta}$ & $0 \boldsymbol{\Delta}$ & $0 \boldsymbol{\Delta}$ \\
\hline Model & 144 & $0 *$ & $6 *$ & $132^{*}$ & $6 *$ \\
\hline Tam & 144 & $18^{*} \boldsymbol{\Delta}$ & $47 * \boldsymbol{\Delta}$ & $78^{*} \boldsymbol{\Delta}$ & $1 * \boldsymbol{\Delta}$ \\
\hline Eug $(1 \mathrm{mg})$ & 144 & $11^{*} \boldsymbol{\Delta}$ & $39 * \boldsymbol{\Delta}$ & $92 * \boldsymbol{\Delta}$ & $2 * \boldsymbol{\Delta}$ \\
\hline Eug $(0.5 \mathrm{mg})$ & 144 & $9 * \boldsymbol{\Delta}$ & $37 * \boldsymbol{\Delta}$ & $94 * \boldsymbol{\Delta}$ & $4 * \boldsymbol{\Delta}$ \\
\hline
\end{tabular}

There are 12 rats in every group and every rat has six pairs of nipples. $* P<0.05$, Model, Eug $(0.5 \mathrm{or} 1 \mathrm{mg})$ - or Tam-treated rats versus normal control rats; $\mathbf{\Delta} P<0.05$, normal control, Eug ( 0.5 or $1 \mathrm{mg})$ - or Tam-treated rats versus breast precancerous lesion model rats (Scheff'e test).

A
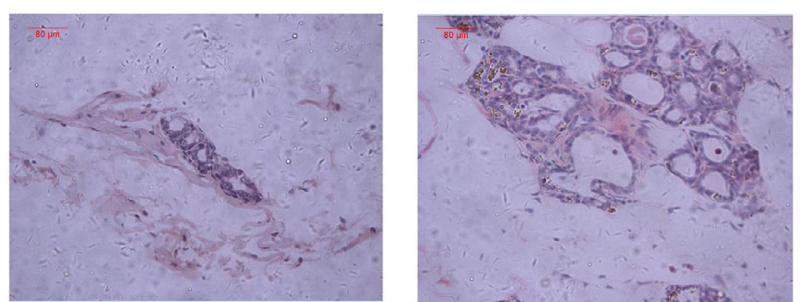

Normal
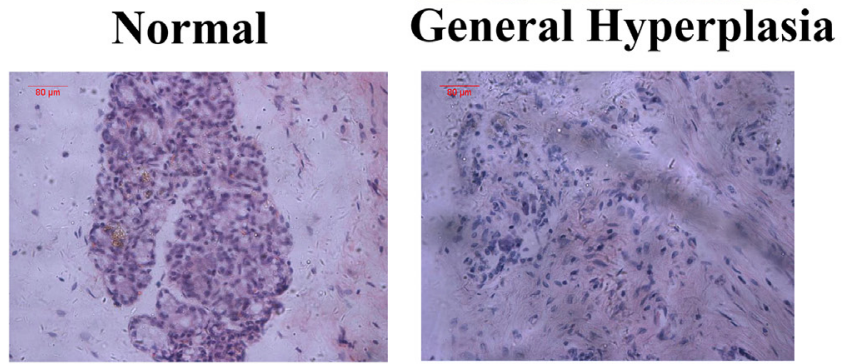

Precancerous lesions Invasive carcinomas

B

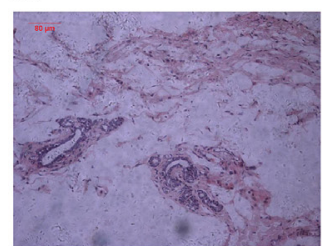

Nor

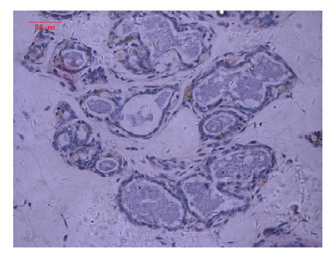

Eug (1 mg)

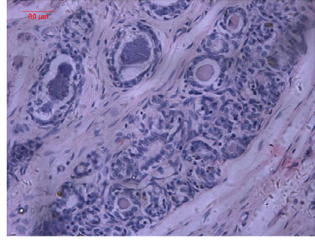

Mod

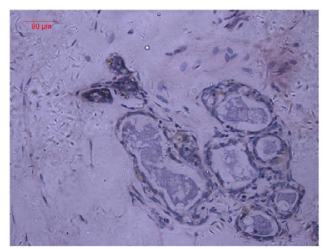

Eug (0.5 mg)

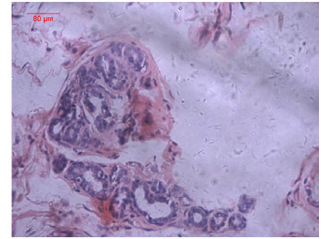

Tam

Figure 6: Breast tissue morphological assay for rats and eugenol (Eug) decreased the occurrence of breast precancerous lesions and invasive carcinomas in breast precancerous lesion model rats. (A) Rats breast tissue morphological detection in the process from normal (Nor), general hyperplasia, precancerous lesions to invasive carcinomas. (B) Breast tissue morphological assay for normal (Nor), tamoxifen (Tam, $1 \mathrm{mg})$-, low $(0.5 \mathrm{mg})$ or high (1 mg) dose Eug-treated breast precancerous lesion model rats after treatment for 14 weeks. 


\section{Effects of Eug on expression of HER2/PI3K- AKT signaling pathway key protein in breast precancerous lesion model rats}

Breast precancerous lesion model rats were established by dimethylbenzanthracene (DMBA) combined estrogen and progesterone. To detect the therapeutic intervention effect of Eug for external use on the progression of breast precancerous lesion, from the beginning of modelling to 14 th week, the rat breasts were smeared with different concentrations of Eug cream once a day. The effects of Eug on expression of HER2/PI3KAKT signaling pathway key proteins were detected using western-blot analysis. The experiment results showed that compared with the normal blank control group, the expressions of HER2, AKT, PDK1, p85, Bcl2, and Cyclin D1 were increased by 1.27-, 0.813-, 2-, 1.136-, 1.107and 0.786 -fold respectively, and Bax protein expression was decreased by $72.9 \%$ in disease model group (Figure 7A and 7B). Compared with the disease model group, after being treated by high dose Eug cream (1 mg Eug), the expressions of HER2, AKT, PDK1, p85, Bcl-2 and Cyclin D1 protein were significantly decreased by $62.9 \%, 58.6 \%$, $56.4 \%, 54.3 \%, 59.3 \%$ and $43.0 \%$ respectively, whereas Bax protein expression was increased by 2.51 -fold. The expressions of these key proteins HER2, AKT and PDK1 were also significantly decreased in Tam-treated group, which were similar with the effects in high dose Eugtreated group (Figure 7A and 7B).

Immunohistochemical assay were also performed using the monoclonal antibodies including NF- $\mathrm{KB}$ p65 $\mathrm{mAb}, \mathrm{p} 21 \mathrm{mAb}, \mathrm{Bad} \mathrm{mAb}$ and $\mathrm{p} 27 \mathrm{mAb}$. The results showed compared with the normal blank control group, the expressions of $\mathrm{NF}-\kappa \mathrm{B}$ and Bad proteins were respectively increased by 3.08- and 3.11-fold, while p 21 and p27 expression was respectively decreased by $1.73-$ and 2.52-fold in the disease model group. Compared with the disease model group, the expressions of $\mathrm{NF}-\kappa \mathrm{B}$ and Bad proteins were significantly decreased in Tam- and Eug cream-treated groups, whereas p21 and p27 expressions were significantly increased, and Eug had a dose dependent effect. In high dose of Eug creamtreated group, the expressions of NF- $\mathrm{kB}$ and Bad proteins were decreased by $65.7 \%$ and $64.0 \%$, while $\mathrm{p} 21$ and $\mathrm{p} 27$ protein expressions were increased by 1.83 - and 2.52 -fold, respectively (Figure $8 \mathrm{~A}$ and $8 \mathrm{~B}$ ).

\section{DISCUSSION}

At present, Eug has been used as antiseptic, analgesic and antibacterial agent [13]. The antiproliferative activity of Eug against melanoma, leukemia, gastric, skin tumor and prostate cancer cells has been confirmed by many research [14], and Eug can induce apoptosis in various cancer cells such as mast cells, melanoma cells and HL-60 leukemia cells [15]. HER2 is the main signal amplifier of this growth factor receptor family, HER2/ PI3K-AKT signaling pathway is an important regulation pathway in the development of breast cancer $[16,17]$. The current study showed that Eug had obviously therapeutic effects on breast precancerous lesions by blocking HER2/ PI3K-AKT signaling transduction.

MCF10A cell is the non-tumorigenic "normal" line and exists low level of HER2 expression [18]. The MCF10AT cell derived from xenograft-passaged MCF10-AneoT cells, generates carcinomas in about $25 \%$ of xenografts, representing the transition from normal epithelium to malignant carcinoma. HER2/ERBB2 levels were elevated in the MCF10-AT cell line. MCF-7 cell is estrogen and progesterone receptor positive luminal A breast cancer cell line, but HER2 expression is weak in MCF-7 cell [19]. BT474, a estrogen positive cell line, was isolated from a solid invasive ductal carcinoma of the breast and overexpresses HER2 [20]. Eug can significantly inhibit proliferation of the HER-2 positive breast precancerous lesion MCF-10AT cells but there was almost no significant inhibitory effect on MCF-7 or MCF-10A cells with HER2 weak expression. Furthermore the antiproliferative or apoptosis-promoting effects of Eug nearly disappeared in MCF-10AT cells with HER2 overexpression. These results indicated that HER-2 in HER2/PI3K-AKT signaling pathway might firstly mediated the antiproliferative or apoptosis-promoting effects of Eug on MCF-10AT cells. HER2 are closely related with the growth, survival, adhesion, metastasis and differentiation of breast cancer cells, and the over-expression of HER2 would increase the tyrosine kinase activity in cells, and the carcinogenic effect of HER2 mainly inhibited apoptosis and promoted tumor angiogenesis and metastasis [21]. In this study, Eug could significantly decrease HER2, p85, PDK1 and AKT protein expressions in a dose-dependent manner in MCF-10AT cells or breast precancerous lesion model rats, which could further promote cell apoptosis and inhibit tumor progression. The over-expression of PI3K regulatory subunit $\mathrm{p} 85$ and its interactions with tyrosinephosphorylated receptor/adaptor proteins may make PI3KAKT pathway keeping sustained activation, further lead to cell abnormal proliferation or apoptosis obstruction [22]. PI3K are heterodimers comprised of a regulatory subunit p85 and a catalytic subunit p110. Activation of PI3Ks may be initiated when a growth factor or ligand binds to HER2 tyrosine kinase. Thus PI3K heterodimer interacts with their intracellular portion via $\mathrm{p} 85$, and the activated kinase catalyses the phosphorylation of phosphatidylinositol4,5-bisphosphate (PIP2) to phosphatidylinositol-3,4,5triphosphate (PIP3). PIP3 acts as a docking site for AKT, a serine/threonine kinase that is the central mediator of the PI3K pathway and phosphoinositide-dependent kinase 1(PDK1). Association with PIP3 at the membrane PDK1 facilitates phosphorylation of AKT. However, the inhibition of $\mathrm{p} 85$ expression or activity not only induced cell apoptosis but also may counteract the over-expression 
of ERBB2 [20-23]. As an upstream protein of AKT, PDK1 may activate AKT and its downstream kinases. PDK1 is over-expressed in most of the cancer cells, and inhibiting the expression of PDK1 followed by decreasing the activity of AKT may become a new treatment strategy for hemangioma [21-24]. Through the phosphorylation of a diverse set of substrates including apoptosis or cell cycle regulators, activated AKT regulates cell-cycle, cell apoptosis or survival. So Eug may effectively inhibited the progress of breast precancerous lesion through blocking HER2/PI3K-AKT signaling transduction by decreasing HER2, p85, PDK1 and AKT protein expressions, inhibiting the conversion of PIP2 to PIP3 and phosphorylation of AKT.

The flow cytometry assay showed Eug could significantly promote cells apoptosis and induce S-phase cell cycle arrest in breast precancerous lesion MCF-10AT cells. Eug or Tam mainly induced the late apoptosis in MCF-10AT cells, it may be that Eug or Tam cause the DNA degradation or breakage of MCF-10AT cells so as to provoke a strong cytotoxic response $[25,26]$. This study showed Eug effectively regulated the expressions of the apoptosis-related factors including NF- $\kappa \mathrm{B}, \mathrm{Bad}$, Bcl-2, Bax and cell cycle regulators p21, p27 and cyclin D1 in breast precancerous lesion model rats. A previous study has suggested that Eug may significantly decrease the NF- $\kappa \mathrm{B}$ expression in a rat model of gastric cancer, and the inhibition of NF- $\kappa \mathrm{B}$ expression or activity was the important mechanism of reducing cell apoptosis $[9,27]$. Some studies have showed that the expression of the Bcl-2 family proteins such as Bax, Bad and $\mathrm{Bcl} 2$ are closely related to the appearance and development of breast cancer [28-30]. Abnormal high expression of the Bad protein promoted prostate cancer growth, and antiapoptotic molecular $\mathrm{Bcl} 2$ and pro-apoptotic molecular Bax constitute an apoptosis switch in cancer development and therapy [31]. The over-expression of $\mathrm{Bcl} 2$ not only prevents the development of cells apoptosis, but inhibits the release of cytochrome $\mathrm{C}$, nevertheless, Bax may increase the membrane's permeability, which leads to the release of cytochrome $\mathrm{C}$ from mitochondria, activation of caspase-9 and initiation of the caspase activation pathway for apoptosis [32, 33]. Western-blot assay showed Eug markedly decreased the protein expressions of NF- $\kappa \mathrm{B}$, $\mathrm{Bcl} 2$ and $\mathrm{Bad}$, meanwhile significantly increased the Bax expression in breast precancerous lesion MCF-10AT cells or model rats. Thus it may be one of the important cell pro-apoptotic mechanisms of Eug through effectively regulating these apoptosis-related factors expressions.

Eug can also inhibit the growth of tumor cells by influencing the cells cycle [9]. This study indicated that Eug could obviously induce $S$-phase cell cycle arrest in breast precancerous lesion MCF-10AT cells, and reduced the protein expression of cyclinD1, meanwhile, increase P21 and p27 protein expression in breast precancerous lesion MCF-10AT cells or model rats. p21, p27, cyclin D1 and cyclin E was often associated with S-phase cell cycle arrest, and p21 and p27 are tumor suppressor proteins that retard the cell cycle progression by binding with active cyclin-CDK complexes and thereby inhibiting

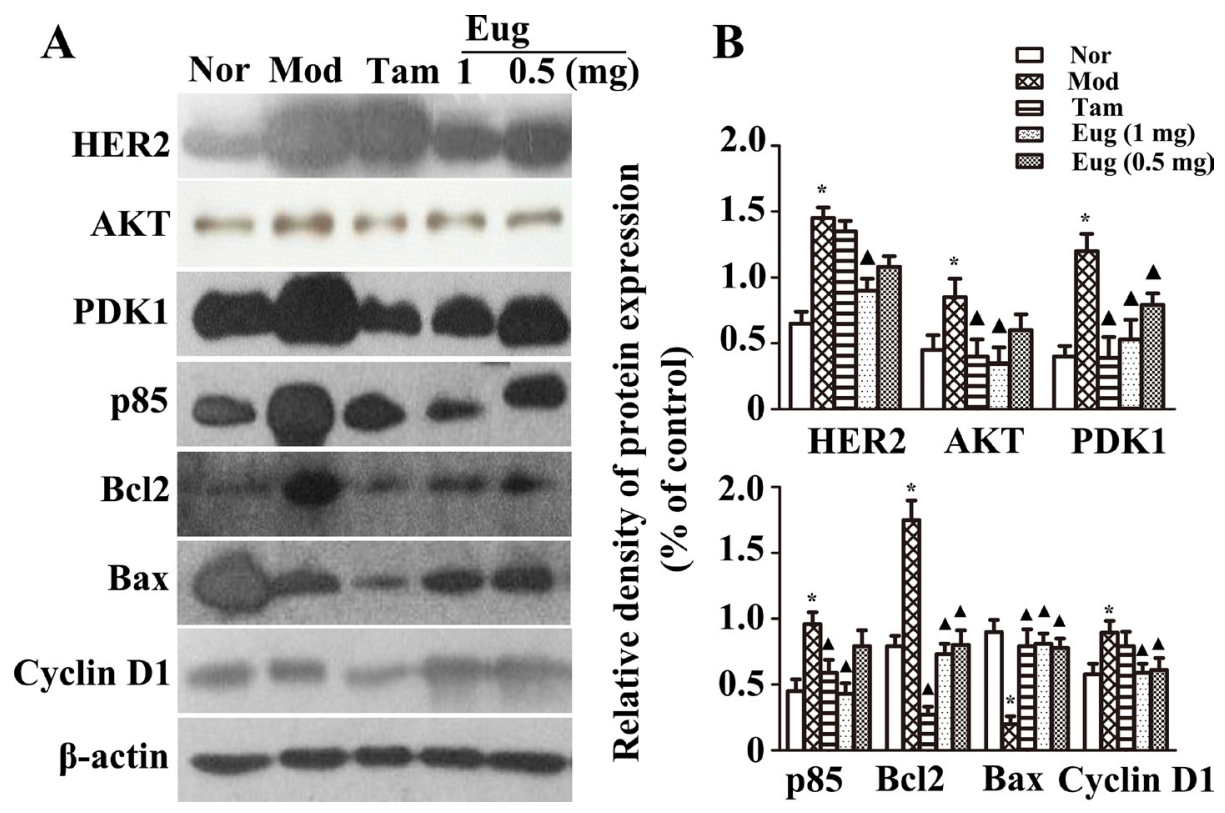

Figure 7: Effect of eugenol (Eug) on the key proteins expression of HER2/PI3K-AKT signaling pathway in normal (Nor) or breast precancerous lesion model (Mod) rat breast tissues. (A) Western-blot assays for the expression of the key proteins HER2, AKT, PDK1, P85, Bcl2, Bax and Cyclin D1 in normal rats or breast precancerous lesion model rats without treatment or continuously treated with tamoxifen (Tam, $1 \mathrm{mg})$, low $(0.5 \mathrm{mg})$ or high $(1 \mathrm{mg})$ dose Eug for 14 weeks. (B) Relative expression assays for HER2, AKT, PDK1, P85, Bcl2, Bax and Cyclin D1 in (A). ${ }^{*} P<0.05$, breast precancerous lesion model rats versus normal control rats; $\Delta P<0.05$, normal control, Eug ( 0.5 or $1 \mathrm{mg}$ )- or Tam-treated rats versus breast precancerous lesion model rats (Scheff ${ }^{\prime}$ e test, $\left.n=12\right)$. 
their activities [34-36]. Furthermore, the over-expression of CyclinD1 is parallel with the tumor rapidly growth, and abnormal high expression of CyclinD1 may cause the disorder of cell cycle and abnormal cell proliferation [37]. Especially, the expression of CDK1, CDK2, Cdc25C and Cyclin A which are mainly involved in driving the transition from $\mathrm{S}$ to $\mathrm{G} 2 / \mathrm{M}$ phase were markedly reduced in HER2 non-overexpressing MCF-10AT cells after Eug treatment, which indicated Eug could inhibit the breast precancerous cells proliferation by inducing S-phase cell cycle arrest.

In brief, this study showed that eugenol external use may effectively alleviate or inhibit breast precancerous lesions through HER2/PI3K-AKT pathway-induced cell apoptosis and S-phase cell cycle arrest, indicating eugenol may be a promising external application drug to prevent or treat breast precancerous lesions.

\section{MATERIALS AND METHODS}

\section{Cell lines}

BT-474, a breast cancer cell line with HER-2 overexpression and breast precancerous lesion cell line MCF-10AT, and breast cancer cell line MCF-7 or MCF$10 \mathrm{~A}$ with weak expression of HER-2 were purchased from American Karmanos cancer research institute (KCI).

The MCF-10AT cell line was monolayer adherent cell, and was cultured in a $37^{\circ} \mathrm{C}$ constant incubator containing 5\% $\mathrm{CO}_{2}$. Complete media (DMEM/F-12 supplemented with $5 \%$ horse serum) was used for MCF10AT cell culture, and the cells at logarithmic growth phase were used in the cytological experiments.

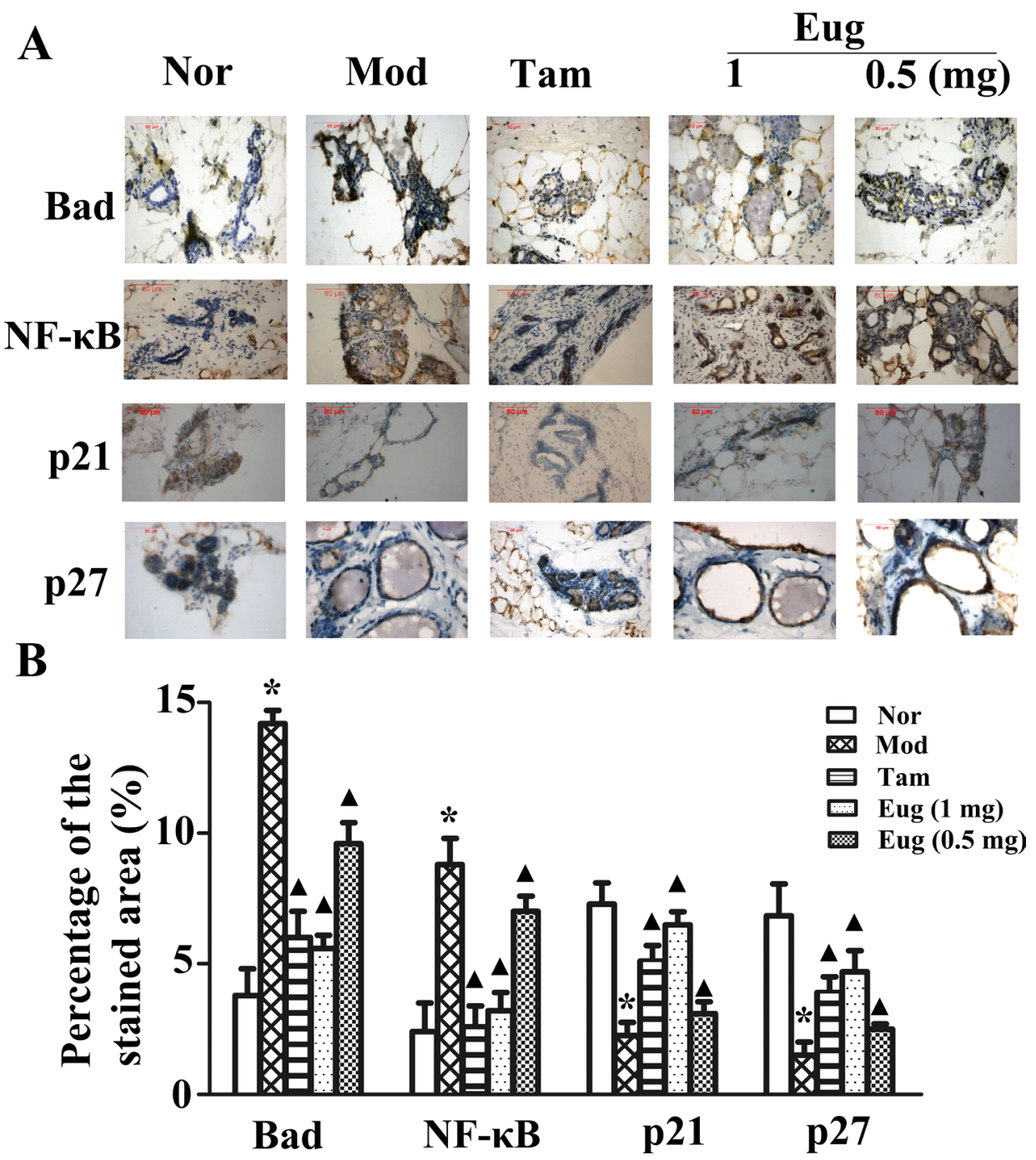

Figure 8: Immunohistochemical assay for the key proteins Bad, NF- $\kappa B$, p21 and p27 of HER2/PI3K-AKT signaling pathway in normal (Nor) or breast precancerous lesion model (Mod) rat breast tissues without treatment or continuously treated with tamoxifen (Tam, $1 \mathrm{mg})$, low $(0.5 \mathrm{mg})$ or high $(1 \mathrm{mg})$ dose Eug for 14 weeks $(\mathbf{A})$ and their relative expression assays $(\mathbf{B})$. $* P<$ 0.05, breast precancerous lesion model rats versus normal control rats; $\boldsymbol{\Delta} P<0.05$, normal control, Eug ( 0.5 or $1 \mathrm{mg})$ - or Tam-treated rats versus breast precancerous lesion model rats (Scheff'e test, $n=12$ ). 


\section{Plasmid preparation and transfection}

The coding sequence of HER2 cDNA was successfully cloned and it was consistent with the NCBI database. Then the eukaryotic expression vector pcDNA3.1-HER2 was constructed and confirmed by sequencing. The cell lines including BT-474, MCF10AT, MCF-7 and MCF-10A with HER2 over-expression were performed by pcDNA3.1-HER2 transfection using Lipofectamine 2000 (Invitrogen, Carlsbad, CA, USA) according to the protocol of manufacturer.

\section{Drug preparation for rat models of breast precancerous lesions}

\section{Preparations of blank matrix and eugenol (Eug) cream}

$7 \mathrm{~g} \mathrm{KOH}$ was dissolved in appropriate amount of distilled water and heated to $80^{\circ} \mathrm{C}$, which was taken as the water phase. $140 \mathrm{~g}$ stearic acid was heated in a water bath, melted and cooled down to $80^{\circ} \mathrm{C} .100 \mathrm{~g} \mathrm{KOH}$ water solution and glycerinum were added and stirred constantly, then the appropriate amount of distilled water was added and the volume was metered to $1000 \mathrm{ml}$, so as to obtain the blank matrix (Mat). The sample was continuously stirred and cooled down to $40^{\circ} \mathrm{C}$. The different doses of Eug were added, thoroughly mixed and cooled down to room temperature, so as to obtain the Eug cream. Per one gram of high or low dose Eug creams respectively contained 5 or $2.5 \mathrm{mg}$ Eug.

\section{Preparation of tamoxifen (Tam) cream}

$0.5 \mathrm{~g}$ Tam and $99.5 \mathrm{~g}$ blank matrix were weighed. The blank matrix was heated to melting, then Tam was slowly added under constant stirring and cooled down to room temperature. Per one gram of Tam cream contained $5 \mathrm{mg}$ Tam.

\section{Preparation of DMBA solution}

The DMBA was precisely weighed, dissolved in sesame oil according to the proportion of $7 \mathrm{mg} / \mathrm{ml}$, placed in ultrasonic constant temperature water bath box $\left(60^{\circ} \mathrm{C}\right.$, $40 \mathrm{~Hz}$ ), and completely dissolved by ultrasonic oscillation.

\section{Effect of Eug on proliferation of the breast precancerous lesion model MCF-10AT cells and BT-474, MCF-7, MCF-10A cells}

$100 \mu \mathrm{l}$ BT-474, MCF-10AT MCF-7 and MCF$10 \mathrm{~A}$ cells suspension at logarithmic phase $\left(5 \times 10^{4}\right.$ cells $/ \mathrm{ml}$ ) were respectively inoculated in each well of 96-well culture plate. After being cultured for $24 \mathrm{~h}$, the different concentrations of Eug medium solution [40, 80, 120, 160, 200 and $240 \mu \mathrm{M}$; Eug was firstly dissolved in dimethyl sulphoxide (DMSO) and then further dissolved in PBS (PH 7.4). The final concentration of DMSO in Eug medium solution was less than $0.1 \%$, and it had no effect on cells] were added. The $50 \%$ inhibiting concentration (IC50) of Eug on MCF-10AT cells and the inhibition rates of $80 \mu \mathrm{M}$ Eug for BT-474, MCF-10AT, MCF-7 and MCF$10 \mathrm{~A}$ cells were detected. The PBS-treated groups were acted as the control groups (Vehicle). The sample was cultured for another $24 \mathrm{~h} .20 \mu \mathrm{l} 5 \mathrm{mg} / \mathrm{ml}$ MTT was added in every well and cultured for $4 \mathrm{~h}$ away from light. The cell growth inhibition rate [growth inhibition rate $(\%)=(1$-experimental group A570/control group A570) $\times 100 \%$ ] was detected.

In cell lines including BT-474, MCF-10AT, MCF7 and MCF-10A with HER 2 over-expression, cells were treated by the same concentration of Eug to detect the biological effect of Eug.

\section{Effect of Eug on MCF-10AT cells apoptosis}

The MCF-10AT cells at logarithmic growth phase inoculated in 6-well plate were treated with PBS, Tam $(180 \mu \mathrm{M})$ or Eug $(180 \mu \mathrm{M})$ for $24 \mathrm{~h}$, then the MCF10AT cells were digested using trypsin-EDTA to obtain MCF-10AT cell suspension $\left(5 \times 10^{5}\right.$ cells $\left./ \mathrm{ml}\right)$. $1 \mathrm{ml}$ MCF-10AT cell suspension was centrifuged by $1000 \mathrm{rpm} / \mathrm{min}$ at $4^{\circ} \mathrm{C}$ for $10 \mathrm{~min}$. After the MCF-10AT cells were resuspended with $200 \mu \mathrm{l}$ binding buffer, $10 \mu \mathrm{l}$ Annexin V-FITC and $10 \mu \mathrm{l}$ propidium iodide (PI) were added, and gently blended for reaction away from light for $15 \mathrm{~min}$. The cell apoptosis rates were detected by the flow cytometry.

In MCF-10AT cells with HER2 overexpression, cells were treated by the same concentration of Eug $(180 \mu \mathrm{M})$ to detect the biological effect of Eug.

\section{Effect of Eug on HER2 non-overexpressing and overexpressing MCF-10AT cell cycle}

The MCF-10AT cells at logarithmic growth phase were inoculated with $1 \times 10^{5}$ cells/well in a 6 -well plate and cultured for $24 \mathrm{~h}$. Then the cells in different groups were respectively treated with PBS, Tam $(180 \mu \mathrm{M})$ or Eug $(180 \mu \mathrm{M})$ for another $24 \mathrm{~h}$. The cells were collected and fixed for $12 \mathrm{~h}$ using the pre-cooling $70 \%$ alcohol at $4^{\circ} \mathrm{C}$. Then the fluorochrome PI was added and incubated at $37^{\circ} \mathrm{C}$ away from light for $30 \mathrm{~min}$. Finally the red fluorescence was detected at $488 \mathrm{~nm}$ excitation wavelength by the flow cytometry, and the cell cycle distributions of MCF-10AT cells in different experimental groups were determined. In MCF-10AT cells with HER2 overexpression, cells were treated by the same concentration of Eug $(180 \mu \mathrm{M})$ to detect the biological effect of Eug. The expression of CDK1, CDK2, Cdc25C and Cyclin A were detected by westernblot analysis as described previously [38]. 


\section{Effect of Eug on HER2/PI3K-AKT signaling pathway key proteins expressions in HER2 non- overexpressing and overexpressing MCF-10AT cells}

After MCF-10AT cells in logarithmic growth phase were treated with Tam $(180 \mu \mathrm{M})$, Eug, PBS or blank matrix (Mat) for $24 \mathrm{~h}$, HER2 protein expressions were assayed (the concentrations of Eug are 100, 140 and $180 \mu \mathrm{M}$ ), and the HER2/PI3K-AKT signaling pathway key proteins expressions including PDK1, p85, AKT, NF-кB, Bad, Bcl-2, Bax, cyclin D1, p21 and p27 (the concentration of Eug is $180 \mu \mathrm{M}$ ) were detected by western-blot analysis as described previously [38]. In MCF-10AT cells with HER2 over-expression, cells were treated by the same concentration of Eug $(180 \mu \mathrm{M})$ to detect the biological effect of Eug.

\section{Establishment of breast precancerous lesion rat model}

Sixty healthy female six-week-old SD rats with weight 160 g-180 g (SPF, license number: SCXK 2013-0002) were fed in animal laboratory management center SPF grade animal room (indoor temperature $25^{\circ} \mathrm{C}$, natural lighting, free diet and regular disinfection) in Jinan University. After environmental adaptation for one week, the rats hair around the breast was removed $(1 \mathrm{~cm}$ diameter with the nipple as the center). The breast precancerous lesion SD rat model was induced using DMBA in combination with estrogen and progesterone as described previously [39-41]. The rats were randomly divided into 5 groups according to their weight (12 per group): normal blank control group, disease model group, Tam-treated group, high dose Eug-treated group and low dose Eugtreated group. The rats were sacrificed and assayed in the 14 th week.

\section{Therapeutic intervention effect of Eug for external use on breast precancerous lesion model rats}

\section{Normal blank control group (Nor)}

The rats received one-time gavage using $1 \mathrm{ml}$ sesame oil/(100 g body weight $)$ and were conventionally fed for 14 weeks.

\section{Breast precancerous lesion model group (Mod)}

The rats received one-time gavage using $1 \mathrm{ml}$ DMBA sesame oil/(100 $\mathrm{g}$ body weight). The next five days acted as a cycle (5-day cycle), and $0.5 \mathrm{mg}$ benzoate estradiol/ (kg body weight) was injected in the medial muscles of hind legs from the first day to the third day. Then $4 \mathrm{mg}$ progesterone/(kg body weight) was injected on the fourth day. The rats were observed on the fifth day. Continuous 12 cycles (5-day cycle) were performed. The rats were conventionally fed for 14 weeks.

\section{Tam group}

Based on the method of the disease model group, from the first day of the first 5-day cycle to the end of the 14th week, $0.2 \mathrm{~g}$ Tam cream (containing $1 \mathrm{mg}$ Tam) was smeared and massaged for $1 \mathrm{~min}$ on the breast of every rat once a day. The rats were conventionally fed for 14 weeks.

\section{High dose Eug group}

Based on the method of the disease model group, from the first day of the first 5-day cycle to the end of the 14th week, $0.2 \mathrm{~g}$ high dose Eug preparation (containing $1 \mathrm{mg}$ Eug) was smeared and massaged for $1 \mathrm{~min}$ on the breast of every rat once a day. The rats were conventionally fed for 14 weeks.

\section{Low dose Eug group}

Based on the method of the disease model group, from the first day of the first 5-day cycle to the end of the 14th week, $0.2 \mathrm{~g}$ low dose Eug preparation (containing $0.5 \mathrm{mg}$ eugenol) was smeared and massaged for $1 \mathrm{~min}$ on the breast of every rat once a day. The rats were conventionally fed for 14 weeks.

\section{Western-blot detection}

The animal experiments were terminated at the end of the 14th week, and RIPA Lysis Buffer (Beyotime Biotechnology, Shanghai, China) was used to extract the total protein of rat breast tissue in different groups. The total protein was separated by $12 \%$ sodium dodecyl sulfate polyacrylamide gel electrophoresis (SDSPAGE) and transferred onto polyvinylidene difluoride membranes (Millipore, Billerica, USA). The membranes were respectively incubated with the HER 2 Rabbit $\mathrm{mAb}$, AKT Rabbit mAb, PI3 Kinase p85 Rabbit mAb, Cyclin D1 Rabbit mAb, Bax antibody, Bcl-2 Rabbit mAb, PDK1 Rabbit $\mathrm{mAb}$ (Cell Signaling Technology, Inc., Boston, USA), NF-кB p65 mAb, p21 mAb-Bad mAb and p27 mAb (Santa Cruz Biotechnology, CA, USA) overnight at $4{ }^{\circ} \mathrm{C}$. The horseradish peroxidase (HRP)-conjugated goat-anti-rabbit IgG (Cell Signaling Technology, Inc., Boston, USA) was used as the second antibody. Protein bands were visualized by using an ECL kit (Santa Cruz Biotechnology) and densitometric analysis of Western blots was performed with Image $\mathrm{J}$ analysis software.

\section{Immunohistochemical detection}

Establishment of breast precancerous lesion rat model and the animal experiments were performed after the approval from the Laboratory Animal Ethics Committee of Jinan University. Animal welfare and experimental procedures were carried out in accordance with the Guide for the Care and Use of Laboratory Animals (Ministry of Science and Technology of China, 2006) and related ethical regulations of Jinan University. 
After the animal experiments were terminated at the end of the 14th week, the paraffin sample of rat breast tissues in different experimental groups were serially sectioned (4 $\mu \mathrm{m})$, conventionally baked, dewaxed and hydrated. The routine immunohistochemical streptavidinperoxidase (SP) procedures were conducted [42]. The protein expression was observed under light microscope. The positive cells expression average area percentage was analyzed using Leica Qwin software. The statistical analysis was conducted.

\section{Statistical analysis}

Results are presented as mean \pm SEM of at least three independent experiments. Differences between groups were analyzed using analysis of variance with SPSS version 15.0 (International Business Machines Corporation, Armonk, New York, USA). Post-hoc analysis was used if the analysis of variance was significant. $P<0.05$ indicated that the difference was statistically significant.

\section{Abbreviations}

HER2: Human epidermal growth factor receptor 2; ER: Estrogen receptor; ERBB2: v-erb-b2 avian erythroblastic leukemia viral oncogene homolog 2; PR: Progesterone receptor; PDK1: 3-Phosphoinositidedependentprotein kinase-1; NF- $\kappa \mathrm{B}$ : nuclear factor$\kappa \mathrm{B}$; Bad: Bcl-2 antagonist of cell death; Bcl-2: B cell lymphoma-2; Bax: Bcl-2-associated X protein; BSLT: brine shrimp lethality test; MTT: 3-(4,5-Dimethylthiazol2-yl)-2,5-Diphenyltetrazolium Bromide; KCI: Karmanos cancer research institute; Eug: eugenol; Mat: matrix; Tam: tamoxifen; DMBA: dimethylbenzanthracene; DMSO: dimethyl sulphoxide; PI: propidium iodide; Nor: Normal blank control group; Mod: Disease model group; SP: streptavidin-peroxidase.

\section{CONFLICTS OF INTEREST}

The authors declare no conflicts of interest.

\section{FINANCIAL SUPPORT}

The current work was supported by National Natural Science Foundation Project of China (no. 81173265, 81473688, 81373314 and 81673979); The Science and Technology Planning Project of Guangdong Province, China (no. 2014A020210015, 2013B090500105 and 2014A020212672); Education Program of China for New Century Excellent Talents (no. NCET-13-0827); Traditional Chinese Medicine Administration Project of Guangdong Province, China (no. 20141070); The Natural Science Foundation of Guangdong Province (no. 2015A030313333, 2015A030313345 and 2016A030313114); Science and
Technology Support Program of Guangzhou, China (no. 2014J4100104 and 201707010245); The Fundamental Research Funds for the Central Universities (no. 21615412 and 21615464). Guangzhou Municipal Enterprise Research and Development Institutions Construction Project (No.201503010064), the Cooperation Ombudsman Workstation Project in Industry, Education and Research of Guangdong Province, China (No.2013B090900010).

\section{REFERENCES}

1. Lakhani SR. The transition from hyperplasia to invasive carcinoma of the breast. J Pathol. 1999; 187:272-78.

2. Hoogerbrugge N, Bult P, de Widt-Levert LM, Beex LV, Kiemeney LA, Ligtenberg MJ, Massuger LF, Boetes C, Manders P, Brunner HG. High prevalence of premalignant lesions in prophylactically removed breasts from women at hereditary risk for breast cancer. J Clin Oncol. 2003; 21:41-45.

3. Li YW, Zhu GY, Shen XL, Chu JH, Yu ZL, Fong WF. Furanodienone induces cell cycle arrest and apoptosis by suppressing EGFR/HER2 signaling in HER2overexpressing human breast cancer cells. Cancer Chemother Pharmacol. 2011; 68:1315-23.

4. Lee CC, Yang HL, Way TD, Kumar KJ, Juan YC, Cho HJ, Lin KY, Hsu LS, Chen SC, Hseu YC. Inhibition of cell growth and induction of apoptosis by Antrodia camphorata in HER-2/neu-overexpressing breast cancer cells through the induction of ROS, depletion of HER-2/ neu, and disruption of the PI3K/Akt signaling pathway. Evidence-Based Complementary and Alternat Med. 2012; 2012:702857.

5. Song AL, Zhang JT, Li JW, Yin YK. [Effect of Curzerene Curing the Animal Model of Breast Precancer Rats on the Blood Rheology and Mammary Microcirculation.] [Article in Chinese]. Chinese Archives of Traditional Chinese Medicine. 2008; 3:004.

6. Zhang GJ, Li DH, Liao R, Tan BZ, Liu YB, Ma Y, Zhang SY, Ma M, Zeng XT, Lin YM, Peng ZL. The study of interference with ruyanneixiao cream on hemorheology and mammary microcirculation of mammary precancer rats. Adv Mat Res. 2012; 554-556:1789-93.

7. Coopey SB, Mazzola E, Buckley JM, Sharko J, Belli AK, Kim EM, Polubriaginof F, Parmigiani G, Garber JE, Smith BL, Gadd MA, Specht MC, Guidi AJ, et al. The role of chemoprevention in modifying the risk of breast cancer in women with atypical breast lesions. Breast Cancer Res Treat. 2012; 136:627-33.

8. Chen WL, Wu YR, Zou TN, Zhang Y, Wang XQ. [The Contrast Study of Regional Introducing Tamoxifen Ionization and Oral Administration of Cyclomastopathy]. [Article in Chinese]. Journal of Kunming Medical University. 2009; 1:029.

9. Jaganathan SK, Supriyanto E. Antiproliferative and molecular mechanism of eugenol-induced apoptosis in cancer cells. Molecules. 2012; 17:6290-304. 
10. Al-Sharif I, Remmal A, Aboussekhra A. Eugenol triggers apoptosis in breast cancer cells through E2F1/survivin down-regulation. BMC Cancer. 2013; 13:600.

11. Kumar PS, Febriyanti RM, Sofyan FF, Luftimas DE, Abdulah R. Anticancer potential of Syzygium aromaticum L. in MCF-7 human breast cancer cell lines. Pharmacognosy Res. 2014; 6:350-54.

12. Hussain A, Brahmbhatt K, Priyani A, Ahmed M, Rizvi TA, Sharma C. Eugenol enhances the chemotherapeutic potential of gemcitabine and induces anticarcinogenic and anti-inflammatory activity in human cervical cancer cells. Cancer Biother Radiopharm. 2011; 26:519-27.

13. Pramod K, Ansari SH, Ali J. Eugenol: a natural compound with versatile pharmacological actions. Nat Prod Commun. 2010; 5:1999-2006.

14. Majeed H, Antoniou J, Fang Z. Apoptotic effects of eugenolloaded nanoemulsions in human colon and liver cancer cell lines. Asian Pac J Cancer Prev. 2014; 15:9159-64.

15. Okada N, Hirata A, Murakami Y, Shoji M, Sakagami H, Fujisawa S. Induction of cytotoxicity and apoptosis and inhibition of cyclooxygenase-2 gene expression by eugenolrelated compounds. Anticancer Res. 2005; 25:3263-69.

16. Oraki Kohshour M, Mirzaie S, Zeinali M, Amin M, Said Hakhamaneshi M, Jalili A, Mosaveri N, Jamalan M. Ablation of breast cancer cells using trastuzumabfunctionalized multi-walled carbon nanotubes and trastuzumab-diphtheria toxin conjugate. Chem Biol Drug Des. 2014; 83:259-65.

17. Raimondi C, Falasca M. Targeting PDK1 in cancer. Curr Med Chem. 2011; 18:2763-69.

18. McElwee JL, Mohanan S, Griffith OL, Breuer HC, Anguish LJ, Cherrington BD, Palmer AM, Howe LR, Subramanian V, Causey CP, Thompson PR, Gray JW, Coonrod SA. Identification of PADI2 as a potential breast cancer biomarker and therapeutic target. BMC Cancer. 2012; 12:500.

19. Martinez-Outschoorn UE, Prisco M, Ertel A, Tsirigos A, Lin Z, Pavlides S, Wang C, Flomenberg N, Knudsen ES, Howell A, Pestell RG, Sotgia F, Lisanti MP. Ketones and lactate increase cancer cell "stemness," driving recurrence, metastasis and poor clinical outcome in breast cancer: achieving personalized medicine via Metabolo-Genomics. Cell Cycle. 2011; 10:1271-86.

20. Emde A, Mahlknecht G, Maslak K, Ribba B, Sela M, Possinger K, Yarden Y. Simultaneous Inhibition of Estrogen Receptor and the HER2 Pathway in Breast Cancer: effects of HER2 Abundance. Transl Oncol. 2011; 4:293-300.

21. Denkert C, Pfitzner BM, Heppner BI, Dietel M. [Molecular pathology for breast cancer: importance of the gene expression profile]. [Article in German]. Pathologe. 2015; 36:145-53.

22. Luo J, Cantley LC. The negative regulation of phosphoinositide 3-kinase signaling by p85 and it's implication in cancer. Cell Cycle. 2005; 4:1309-12.
23. Park SW, Zhou Y, Lee J, Lu A, Sun C, Chung J, Ueki K, Ozcan U. The regulatory subunits of PI3K, p85alpha and p85beta, interact with XBP-1 and increase its nuclear translocation. Nat Med. 2010; 16:429-37.

24. Yang ZY, Di MY, Yuan JQ, Shen WX, Zheng DY, Chen JZ, Mao C, Tang JL. The prognostic value of phosphorylated Akt in breast cancer: a systematic review. Sci Rep. 2015; 5:7758.

25. Wan X, Zheng X, Pang X, Zhang Z, Zhang Q. Incorporation of lapatinib into human serum albumin nanoparticles with enhanced anti-tumor effects in HER2-positive breast cancer. Colloids Surf B Biointerfaces. 2015; 136:817-27.

26. Baskić D, Popović S, Ristić P, Arsenijević NN. Analysis of cycloheximide-induced apoptosis in human leukocytes: fluorescence microscopy using annexin V/propidium iodide versus acridin orange/ethidium bromide. Cell Biol Int. 2006; 30:924-32.

27. Manikandan P, Vinothini G, Vidya Priyadarsini R, Prathiba D, Nagini S. Eugenol inhibits cell proliferation via NF- $\kappa B$ suppression in a rat model of gastric carcinogenesis induced by MNNG. Invest New Drugs. 2011; 29:110-17.

28. Wolter KG, Hsu YT, Smith CL, Nechushtan A, Xi $\mathrm{XG}$, Youle RJ. Movement of Bax from the cytosol to mitochondria during apoptosis. J Cell Biol. 1997; 139:1281-92.

29. Yang J, Liu X, Bhalla K, Kim CN, Ibrado AM, Cai J, Peng TI, Jones DP, Wang X. Prevention of apoptosis by Bcl2: release of cytochrome c from mitochondria blocked. Science. 1997; 275:1129-32.

30. Choudhuri T, Pal S, Agwarwal ML, Das T, Sa G. Curcumin induces apoptosis in human breast cancer cells through p53dependent Bax induction. FEBS Lett. 2002; 512:334-40.

31. Farsinejad S, Gheisary Z, Ebrahimi Samani S, Alizadeh AM. Mitochondrial targeted peptides for cancer therapy. Tumour Biol. 2015; 36:5715-25.

32. Dembowy J, Adissu HA, Liu JC, Zacksenhaus E, Woodgett JR. Effect of glycogen synthase kinase-3 inactivation on mouse mammary gland development and oncogenesis. Oncogene. 2015; 34:3514-26.

33. Narita M, Shimizu S, Ito T, Chittenden T, Lutz RJ, Matsuda $\mathrm{H}$, Tsujimoto Y. Bax interacts with the permeability transition pore to induce permeability transition and cytochrome c release in isolated mitochondria. Proc Natl Acad Sci USA. 1998; 95:14681-86.

34. Chen T, Wong YS. Selenocystine induces S-phase arrest and apoptosis in human breast adenocarcinoma MCF-7 cells by modulating ERK and Akt phosphorylation. J Agric Food Chem. 2008; 56:10574-81.

35. Wu J, Omene C, Karkoszka J, Bosland M, Eckard J, Klein $\mathrm{CB}$, Frenkel K. Caffeic acid phenethyl ester (CAPE), derived from a honeybee product propolis, exhibits a diversity of anti-tumor effects in pre-clinical models of human breast cancer. Cancer Lett. 2011; 308:43-53.

36. Yadav V, Varshney P, Sultana S, Yadav J, Saini N. Moxifloxacin and ciprofloxacin induces S-phase arrest and 
augments apoptotic effects of cisplatin in human pancreatic cancer cells via ERK activation. BMC Cancer. 2015; 15:581.

37. Abdel-Fatah TM, Perry C, Dickinson P, Ball G, Moseley P, Madhusudan S, Ellis IO, Chan SY. Bcl2 is an independent prognostic marker of triple negative breast cancer (TNBC) and predicts response to anthracycline combination (ATC) chemotherapy (CT) in adjuvant and neoadjuvant settings. Ann Oncol. 2013; 24:2801-07.

38. Ma Y, Zhao S, Shen S, Fang S, Ye Z, Shi Z, Hong A. A novel recombinant slow-release TNF $\alpha$-derived peptide effectively inhibits tumor growth and angiogensis. Sci Rep. 2015; 5:13595.

39. Turan VK, Sanchez RI, Li JJ, Li SA, Reuhl KR, Thomas PE, Conney AH, Gallo MA, Kauffman FC, Mesia-Vela $\mathrm{S}$. The effects of steroidal estrogens in ACI rat mammary carcinogenesis: 17 $\beta$-estradiol, 2-hydroxyestradiol, 4-hydroxyestradiol, 16 $\alpha$-hydroxyestradiol, and 4-hydroxyestrone. J Endocrinol. 2004; 183:91-99.

40. Russo J, Russo IH. Experimentally induced mammary tumors in rats. Breast Cancer Res Treat. 1996; 39:7-20.

41. Ma M, Li DH, Zhang GJ, Liao R, Tan BZ. Study of Rats“ Mammary Precancer models-induced by DMBA combined estrogen and progesterone. Human Health and Biomedical Engineering (HHBE), 2011 International Conference on: IEEE, 2011; 1292-5.

42. Park YA, Lee JW, Choi JJ, Jeon HK, Cho Y, Choi C, Kim TJ, Lee NW, Kim BG, Bae DS. The interactions between MicroRNA-200c and BRD7 in endometrial carcinoma. Gynecol Oncol. 2012; 124:125-33. 